\title{
PERUBAHAN TUTUPAN HUTAN MANGROVE DI PESISIR KABUPATEN LAMPUNG TIMUR
}

\section{(MANGROVE FOREST COVER CHANGE ALONG THE COAST OF EAST LAMPUNG REGENCY)}

\author{
Yuliasamaya, Arief Darmawan, dan Rudi Hilmanto \\ Jurusan Kehutanan, Fakultas Pertanian, Universitas Lampung \\ Jl. Prof. Dr. Sumantri Brojonegoro No.1 Bandar Lampung, 35145 \\ E-mail: yuliasamaya91@yahoo.com
}

\begin{abstract}
ABSTRAK
Penelitian ini bertujuan untuk: (1) mendeskripsikan perubahan tutupan hutan mangrove di sepanjang pesisir Kabupaten Lampung Timur kurun tahun 1973, 1983, 1994, 2004, dan 2013; (2) menentukan faktor-faktor pemicu perubahan tutupan tersebutkurun tahun 1973-2013. Metode penelitian yang digunakan dalam penelitian ini terdiri atas dua metode antara lain dengan analisis spasial dan metode penelitian deskriptif kualitatif. Penelitian ini dilaksanakan di sepanjang Pesisir Kabupaten Lampung Timur selama bulan Oktober 2013 hingga Maret 2014.Hasil penelitian menunjukkanbahwapada tahun 1973-1983 tutupan mangrove tersebut bertambah seluas 2.541,22 ha, tahun 1983-1994 berkurang seluas 4.903,54 ha, tahun 19942004 berkurang seluas 6.377,11 ha,dan tahun 2004-2013 berkurang seluas 3.059,23 ha.Faktorpemicu yang terjadi di pesisir Lampung Timurpadakurunwaktutersebutantara lain: terjadi perubahan status pengelolaan kawasan di Taman Nasional Way Kambas (TNWK), munculnya masyarakat pendatang di Labuhan Maringgai yang membuka areal mangrove, terdapat aktivitas nelayan di kawasan TNWK, transmigrasi di Labuhan Maringgai, pembuatan tambak-tambak tradisional di Pasir Sakti, terdapat penetapan Peraturan Daerah Kabupaten Lampung Timur Nomor: 03 Tahun 2002 tentang Rehabilitasi Pesisir, Pantai dan Laut dalam Wilayah Kabupaten Lampung Timur, dan berbagai upaya pelestarian mangrove bersama Lampung Mangrove Center (LMC) di Labuhan Maringgai dan kelompok pelestari mangrove, Mutiara Hijau I di Pasir Sakti.
\end{abstract}

Kata kunci:mangrove, perubahan tutupan lahan, GIS, Pesisir Lampung Timur

\begin{abstract}
The purposes of this study were: (1)to describethe change of mangrove forest cover along the coast of East Lampung Regency using Landsat data for 1973, 1983, 1994, 2004, and 2013; (2)todetermine triggering factors that occur in the coast of East Lampung Regency during the years 1973-2013 related to the mangrove forest change. The methods used in the study are spatial analysis and qualitative descriptive method. The study was conducted along the coast of East Lampung Regency over period of October 2013-March 2014.The result shows that: in 1973-1983 increased by 2.541,22 ha, in 1983-1994 decreased by 4.903,54 ha, in 19942004 decreased by 6.377,11 ha, in 2004-2013 decreased by 3.059,23 ha. The related factors that occur in there werechanges in the status management area is happening in Way Kambas National Park (TNWK), there were people migration into Labuhan Maringgai that cutting mangrove, there were fishermen activity in TNWK, transmigration program in Labuhan Maringgai, and land clearing into ponds in Pasir Sakti, the local government issued a regulation:Peraturan Daerah Kabupaten Lampung Timur Nomor: 03 Tahun 2002
\end{abstract}


(Rehabilitation of Coastal, Coastal and Marine in East Lampung regency), and many mangrove conservating program organized by Lampung Mangrove Center (LMC) in Labuhan Maringgai and mangrove conservator group (Mutiara Hijau I) in Pasir Sakti.

Keyword: mangrove, land cover change, GIS, coast of East Lampung Regency

\section{PENDAHULUAN}

Berdasarkan informasi yang didapatkan dari Wetlands (2009), Lampung merupakan provinsi yang memiliki luasan hutan mangrove ke tiga terkecil di Sumatera. Luasan hutan mangrove terbesar dimiliki oleh Provinsi Riau kemudian disusul oleh Sumatera Selatan, sedangkan luasan hutan mangrove terkecil dimiliki oleh Provinsi Bengkulu kemudian Sumatera Barat dan Lampung.

Hutan mangrove di Lampung berada di sepanjang $896 \mathrm{~km}$ dari total panjang pantai sepanjang $1.105 \mathrm{~km}$ (Priyanto, 2012). Keberadaan hutan mangrove yang menutupi sekitar $81 \%$ pantai Lampung ini dapat memberikan berbagai manfaat, di antaranya ialah sebagai stabilitator kondisi pantai, mencegah terjadinya abrasi dan intrusi air laut, sebagai sumber keanekaragaman biota akuatik dan non akuatik, sebagai sumber bahan yang dapat dikonsumsi masyarakat dan lain sebagainya.

Keberadaan hutan mangrove dapat memberikan banyak manfaat, baik secara fisik, biologis, maupun ekonomi, namun pemanfaatan yang berlebihan (khususnya pemanfaatan ekonomi) oleh masyarakat dapat menyebabkan kerusakan ekosistemnya. Menurut Priyanto (2012), kerusakan ekosistem mangrove disebabkan oleh adanya pembukaan kawasan untuk dijadikan lahan tambak udang. Adapun kerusakan tersebut mencapai 48\% (Watala, 2012).

Sebagaimana yang termuat dalam Atlas Sumberdaya Wilayah Pesisir Lampung (Wiryawan, et al., 1999), kawasan pesisir sepanjang pantai Lampung Timur yang tidak termasuk Taman Nasional Way Kambas (TNWK), hampir seluruh bagiannya telah diubah dari rawa-rawa dan hutan mangrove menjadi lahan pertanian padi dan tambak udang windu. Adapun tambak-tambak tersebut di antaranya terdiri atas sebagian besar tambak tradisional, dan sisanya adalah tambak semi-intensif dan intensif. Konversi lahan tersebut diawali dari pinggir pantai, kemudian dilanjutkan dengan konversi lahan yang menuju ke arah daratan.

Kerusakan lahan di pesisir Kabupaten Lampung Timur membuat berbagai pihak melakukan berbagai upaya penanggulangan, baik yang bersifat lokal maupun nasional. Upaya-upaya tersebut dilakukan oleh pemerintah provinsi maupun pemerintah kabupaten, masyarakat setempat, Lembaga Swadaya Masyarakat (LSM), perguruan tinggi, dan lain-lain. Upaya penanggulangan kerusakan lahan pesisir tersebut terdiri atas kegiatan rehabilitasi lahan kritis seperti penanaman mangrove.

Informasi mengenai perubahan tutupan hutan mangrove di pesisir Kabupaten Lampung Timur begitu penting, namun sejauh ini belum ada penelitian yang dilakukan untuk menghasilkan informasi tersebut. Adapun dengan demikian, maka dalam penelitian ini dihasilkan informasi berupa data trend perubahan tutupan hutan mangrove beserta faktor pemicunya, sehingga bermanfaat bagi perencanaan rehabilitasi dan pelestarian mangrove di masa mendatang.

Tujuan dari penelitian ini adalah: (1) mendeskripsikan perubahan tutupan hutan mangrove di sepanjang pesisir Kabupaten Lampung Timur kurun tahun 1973, 1983, 1994, 2004, dan 2013; (2) menentukan faktor-faktor pemicu perubahan tutupan hutan mangrove tersebut kurun tahun 1973-2013. 


\section{METODE PENELITIAN}

Penelitian dilaksanakan pada bulan Oktober 2013hingga Maret 2014 dan berlokasi di seluruh daerah pesisir Lampung Timur. Adapun alat yang digunakan dalam penelitian ini meliputi perangkat keras, perangkat lunak, dan alat tulis. Perangkat keras yang digunakan adalah Personal Computer (PC), Global Posotioning System (GPS), dan kamera. Sedangkan perangkat lunak yang digunakan adalah ERDAS 8.5, ArcGIS 10, Microsoft Word 2010 dan Microsoft Excell 2010.

Data yang dipergunakan dalam penelitian ini adalah data primer dan data sekunder. Data primer yang digunakan adalah: (1) Data citra Landsat path 123/132 row 63-64 dengan perekaman peta pada tahun 1973, 1983, 1994, 2004, 2013; (2) hasil wawancara; (3) dokumentasi dan temuan saat observasi lapang. Data sekunder mencakup data yang telah tersedia baik dari studi pustaka,serta dokumentasi dan publikasi instansi terkait.

Teknik analisis data primer dilakukan dengan dua metode. Data primer berupa citra Landsat dianalisis dengan metode Maximum Likehood dengan menggunakan Penginderaan Jauh dan Geographic Information System (GIS) (Darmawan, 2002). Sedangkan data primer berupa hasil wawancara dan observasi lapang dianalisis secara deskriptif kualitatif.

Adapun dalam penelitian ini data citra Landsat yang diunduh dari http://earthexplorer.usgs.gov/ ${ }^{1}$ dikoreksi dan di-overlay dengan peta digital batas administrasi Kabupaten Lampung Timur kemudian diklasifikasi sehingga menghasilkan peta tutupan mangrove dengan akurasi yang cukup tinggi. Peta tutupan mangrove tersebut kemudian dianalisis sehingga menghasilkan trend perubahan tutupan mangrove yang dideskripsikan beserta dengan faktor-faktor pemicunya selama kurun tahun 1973-2013. Langkah-langkah penelitian tersebut dijabarkan pada gambar berikut ini.

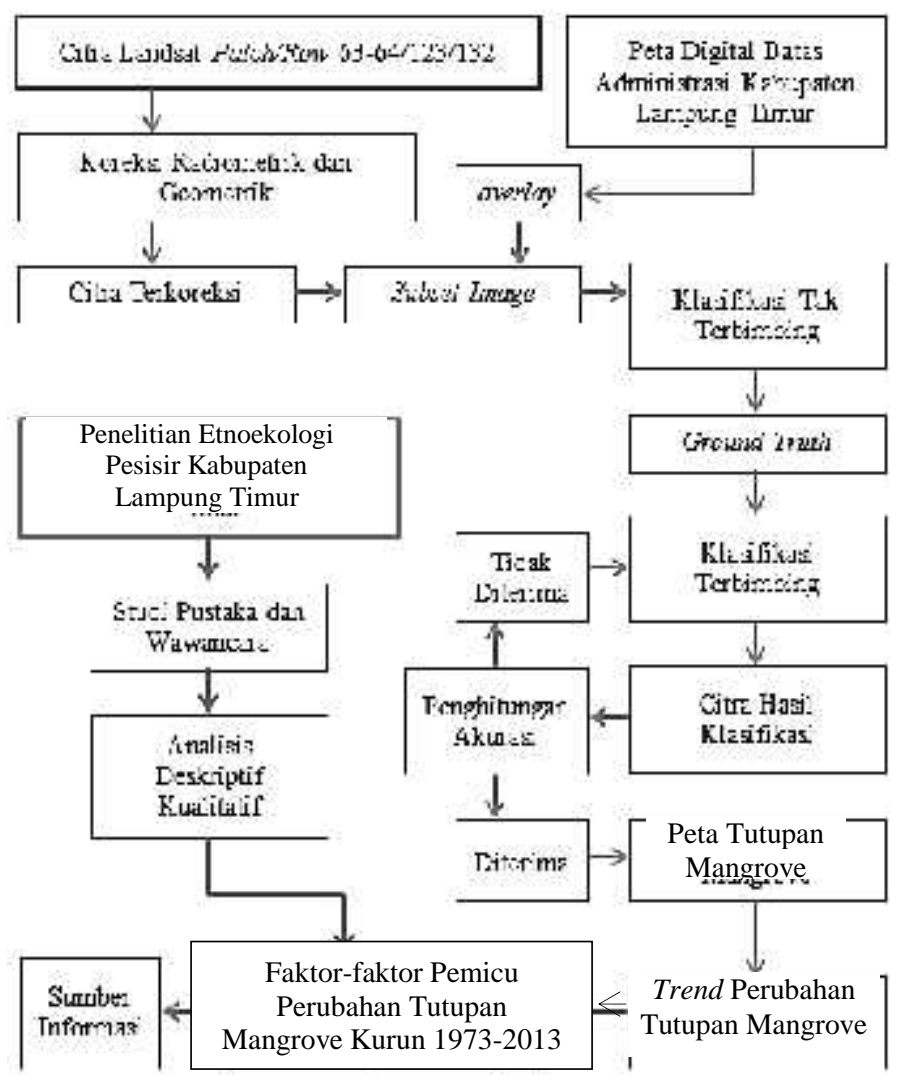

Gambar 1. Skema alur penelitian

\footnotetext{
${ }^{1}$ USGS EarthExplorer. United States Geological Survey. http://earthexplorer.usgs.gov/
} 


\section{HASIL DAN PEMBAHASAN}

\section{A. Perubahan Tutupan Hutan Mangrove di Taman Nasional Way Kambas (TNWK)}

Berdasarkan analisis spasial yang dilakukan di TNWK pada kurun tahun 1973-2013, maka dihasilkan kenampakan tutupan hutan mangrove dalam rata-rata interval 10 tahun antara lain sebagai berikut.

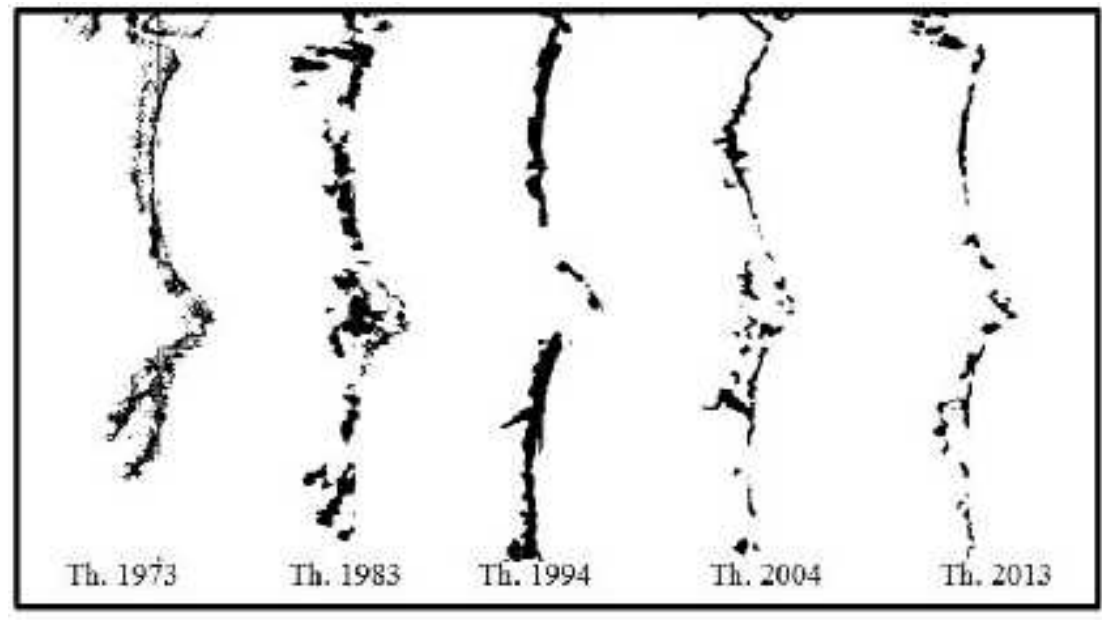

Gambar 2. Perubahan tutupan hutan Mangrove di TNWK tahun 1973-2013

Adapun selain itu, diperoleh pula besaran luasan tutupan hutan mangrove dan persentase perubahannya antara lain disajikan pada tabel berikut.

Tabel 1. Perubahan luasan tutupan hutan mangrove di TNWK

\begin{tabular}{crrr}
\hline No. & Tahun & $\begin{array}{c}\text { Luas Tutupan hutan mangrove } \\
\text { di Taman Nasional Way Kambas }\end{array}$ & Besar Perubahan \\
\hline 1 & 1973 & $12.514,60 \mathrm{ha}$ & $+21,90 \%$ \\
2 & 1983 & $15.255,29 \mathrm{ha}$ & $-8,53 \%$ \\
3 & 1994 & $13.954,01 \mathrm{ha}$ & $-41,02 \%$ \\
4 & 2004 & $8.230,08 \mathrm{ha}$ & $-54,75 \%$ \\
5 & 2013 & $3.724,11 \mathrm{ha}$ & \\
\hline
\end{tabular}

Sumber: Data Primer (2013)

Berdasarkan data yang diperoleh tersebut, maka trend perubahantutupan hutan mangrove di TNWK dapat disajikan pada gambar berikut.

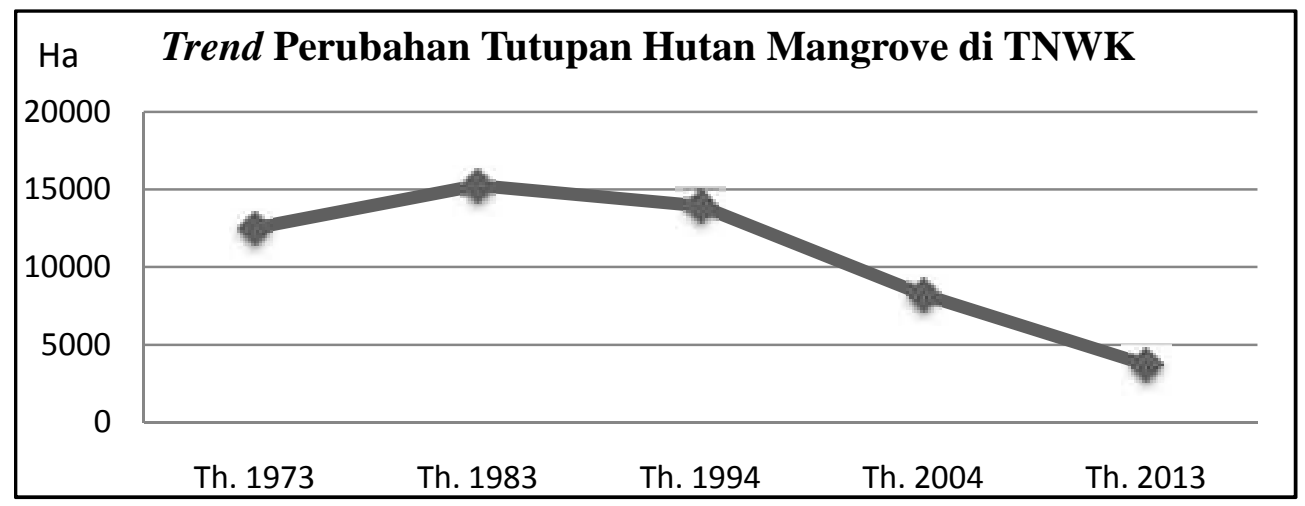

Gambar 3. Trend perubahan luasan tutupan mangrove di TNWK pada tahun 1973-2013 
Berdasarkan data yang diperoleh, tampak bahwa perubahan luasan tutupan mangrove di TNWK cenderung terus menurun sejak tahun 1983 hingga tahun 2013. Adapun peningkatan luasan tutupan mangrove sejak tahun 1973 hingga tahun 1983 tampak tidak lebih besar dari penurunan luasan pada tahun-tahun berikutnya tersebut. Perbedaan tersebut selain dapat dilihat dengan data berupa luasan dalam satuan hektar, dapat pula dilihat secara spasial. Secara kenampakan spasial pada tahun 1973 hingga tahun 1983 tutupan mangrove terlihat semakin terdistribusi merata hampir ke seluruh pesisir kawasan, kemudian pada tahun 1983 hingga tahun 2013 tutupan mangrove terlihat semakin menipis.

Adapun peningkatan luasan tutupan mangrove di TNWK selama rentang tahun 1973 hingga tahun 1983 terjadi seiring dengan adanya perubahan status pengelolaan kawasan hutandi Way Kambas. Perubahan status tersebut antara lainSuaka Margasatwa Way Kambas yang ditetapkan pada tahun 1937 diubah menjadi Kawasan Pelestarian Alam (KPA) pada tahun 1978 (BTNWK, 2011). Perbedaan yang tampak dari adanya hal tersebut yaitu kawasan suaka margasatwa dapat dilakukan pembinaan demi kelangsungan hidup satwa di dalamnya, sedangkan KPA dapat dilakukan pembinaan tidak hanya demi kelangsungan hidup satwa di dalamnya tetapi juga bagi kepentingan pemanfaatan sumberdaya di dalamnya secara lestari. Hal tersebut menunjukkan adanya perubahan fokus pembinaan yang terjadi di dalam Kawasan Hutan Way Kambas. Perubahan fokus pembinaan berpengaruh terhadap sumber daya alam yang terdapat di dalamnya termasuk vegetasi seperti mangrove.

Penurunan luasan tutupan mangrove di TNWK selama rentang tahun 1983 hingga tahun 2013 terjadi seiring dengan beberapa faktor yang terjadi di kawasan tersebut. Faktorfaktor tersebut antara lain adanya perubahan status kawasan, adanya aktivitas nelayan dalam kawasan dan pemberantasan kasus perambahan.

Perubahan status kawasan di Way Kambas yang terjadi kemudian adalah dari KPA status Way Kambas diubah menjadi Kawasan Konservasi Sumber Daya Alam (KSDA) pada tahun 1985 (BTNWK, 2011). Kemudian, pada tahun 1989 Way Kambas dideklarasikan menjadi kawasan taman nasional dan pada tahun 1991 ditetapkan sebagai taman nasional (BTNWK, 2011). Perubahan status kawasan ini membuat pengelolaan kawasan cenderung lebih terarah dengan adanya sistem zonasi yang membagi kawasan menjadi areal-areal yang memiliki fungsi berbeda-beda. Keberadaan mangrove di kawasan TNWK sebagian besar berada di zona rimba, namun ada pula yang berada di zona inti dan zona pemanfaatan intensif (Kenedie, 2010).

Adapun sejak tahun 1996 mulai terdapat aktivitas nelayan di dalam kawasan (wawancara langsung dengan Marjulis dan Teja). Hal ini terjadi akibat menurunnya hasil tangkapan nelayan yang bermukim di sekitar perbatasan Way Kambas. Menurut narasumberpenurunan hasil tangkapan nelayan tersebut dikarenakan oleh kerusakan lingkungan perairan setempat akibat abrasi.

Keberadaan aktivitas nelayan di kawasan TNWK memberikan pengaruh buruk bagi kelangsungan konservasi sumber daya alam di dalam kawasan, khususnya kondisi di pesisir. Hal tersebut melatarbelakangi adanya pemberantasan kasus perambahan yang terjadi sejak tahun 1999 hingga tahun 2008 (wawancara denganMarjulis). Pemberantasan tersebut terjadi di Kuala Kambas, Sekapuk, dan Wako dengan terdapatnya populasi perambah terakhir pada tahun 2008 sekitar 550 KK dan berbagai bangunan semi permanen (BTNWK, 2011; dan wawancara langsung dengan Marjulis).

\section{B. Perubahan Tutupan Hutan Mangrove di Labuhan Maringgai}

Berdasarkan analisis spasial yang dilakukan di Labuhan Maringgai pada kurun tahun 1973-2013, maka dihasilkan kenampakan tutupan hutan mangrove dalam rata-rata interval 10 tahun antara lain sebagai berikut. 


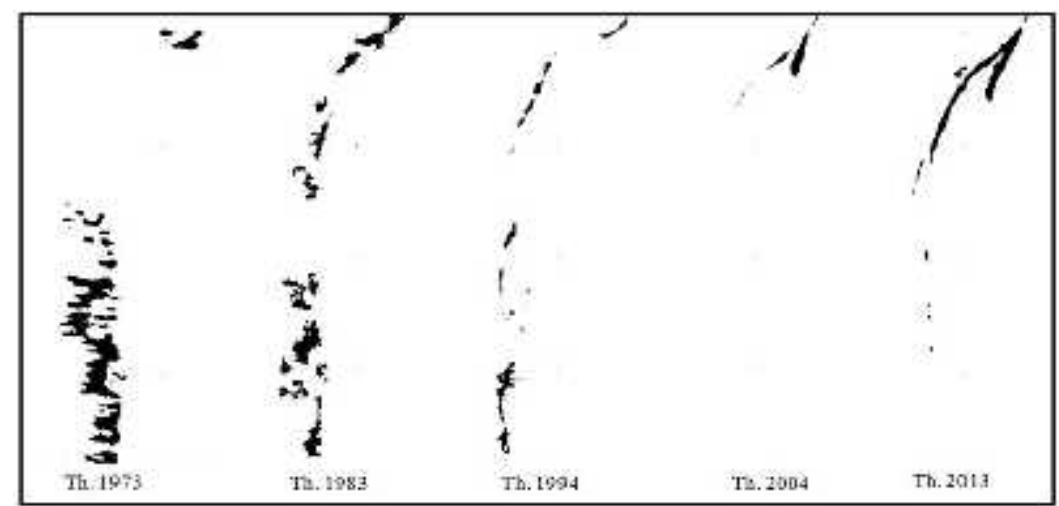

Gambar 4. Perubahan tutupan hutan mangrove di Labuhan Maringgai tahun 1973-2013

Adapun selain itu, diperoleh pula besaran luasan tutupan hutan mangrove dan persentase perubahannya antara lain disajikan pada tabel berikut.

Tabel 2. Perubahan luasan tutupan hutan mangrove di Labuhan Maringgai

\begin{tabular}{ccrr}
\hline No. & Tahun & $\begin{array}{c}\text { Luas Tutupan } \\
\text { hutan mangrove } \\
\text { di Labuhan Maringgai }\end{array}$ & Besar Perubahan \\
\hline 1 & 1973 & $2.373,29 \mathrm{ha}$ & $-23,04 \%$ \\
2 & 1983 & $1.826,48 \mathrm{ha}$ & $-65,69 \%$ \\
3 & 1994 & $626,67 \mathrm{ha}$ & $+14,79 \%$ \\
4 & 2004 & $719,35 \mathrm{ha}$ & $+62,12 \%$ \\
5 & 2013 & $1.166,21 \mathrm{ha}$ & \\
\hline
\end{tabular}

Sumber: Data Primer (2013)

Berdasarkan data yang diperoleh tersebut, maka trend perubahantutupan hutan mangrove di Labuhan Maringgai dapat disajikan pada gambar berikut.

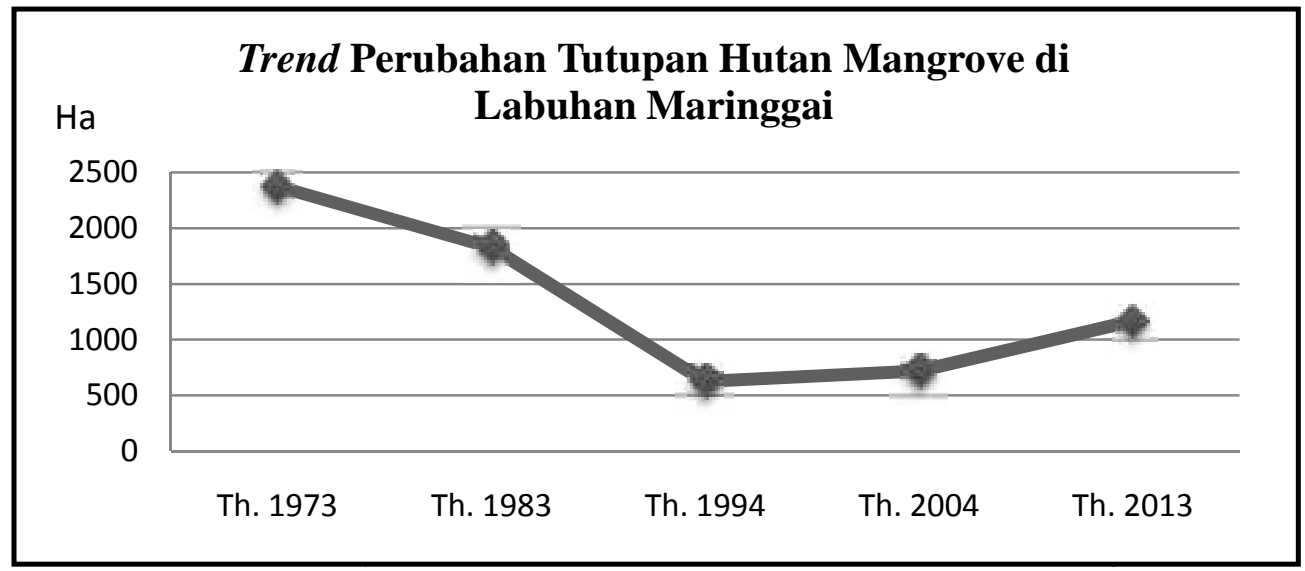

Gambar 5. Trend perubahan luasan tutupan mangrove di Labuhan Maringgai pada tahun 1973-2013

Berdasarkan data yang diperoleh di atas, tampak bahwa perubahan luasan tutupan mangrove cenderung terus menurun pada rentang tahun 1973 ke tahun 1994, kemudian meningkat hingga tahun 2013. Adapun peningkatan luasan tutupan mangrove sejak tahun 1994 hingga tahun 2013 belum dapat melampaui luasan tutupan mangrove di tahun-tahun sebelumnya. Trend tersebut selain dapat dilihat dengan data berupa luasan dalam satuan hektar, dapat pula dilihat secara spasial. Secara kenampakan spasial pada rentang tahun 1973 
ke tahun 1994 tutupan mangrove semakin menipis, walaupun mangrove cenderung terdistribusi merata di sepanjang pantai pada tahun 1983. Pada tahun 1994 mangrove terlihat hampir lenyap kemudian pada tahun 2004 mangrove hanya berada di daerah utara saja (Desa Margasari). Pada tahun 2013 kenampakan tutupan mangrove menunjukkan perbedaan yang sangat jelas dibandingkan pada tahun 1973. Pada tahun 1973 tutupan mangrove cenderung lebih tebal di daerah selatan (Desa Karya Makmur hingga Desa Muara Gading Mas), sedangkan pada tahun 2013 cenderung tebal di daerah utara (Desa Margasari dan Desa Sriminosari).

Adapun penurunan luasan tutupan mangrove di Labuhan Maringgai selama rentang tahun 1973 ke tahun 1994 terjadi seiring dengan adanya beberapa faktor yang terjadi di lokasi setempat. Faktor-faktor tersebut di antaranya adalah munculnya masyarakat pendatang yang membuka hutan mangrove untuk dijadikan tambak udang tradisional dan terdapat program transmigrasi di daerah pesisir setempat.

Munculnya masyarakat pendatang ke daerah pesisir Labuhan Maringgai dimulai pada tahun 1960-an dan pada tahun 1970-an mereka mulai membuka hutan mangrove untuk dijadikan ladang padi dan tambak udang tradisional. Tanggul yang berada di tepi pantai mulai rusak sekitar tahun 1980-an, dan ini mengakibatkan air laut masuk ke arah daratan dengan cepat dan terjadi abrasi (Pariwono, 1999). Fenomena ini mengindikasikan adanya ekploitasi mangrove yang kemudian berdampak pada terhambatnya pertumbuhan mangrove sehingga sulit untuk kembali tumbuh melampaui kondisi awalnya.

Selain eksploitasi mangrove karena pengalihfungsian lahan, di Pesisir Labuhan Maringgai terdapat pula program transmigrasi dengan daerah tujuan Desa Muara Gading Mas. Adapun pada program ini didapatkan keterangan mengenai terdapatnya pembukaan hutan, degradasi mangrove dan peningkatan abrasi di lokasi setempat. Kerusakan-kerusakan lingkungan tersebut diketahui lebih lanjut disebabkan oleh adanya program transmigrasi dengan daerah tujuan di lokasi setempat serta terdapat aktivitas masyarakat setempat yang berlebihan (Nugroho, et al., 2010).

Peningkatan luasan tutupan mangrove di Labuhan Maringgai selama rentang tahun 1994 ke tahun 2013 terjadi seiring dengan beberapa faktor yang terjadi di lokasi setempat. Faktor-faktor tersebut antara lain adanya tanah timbul, munculnya masyarakat pelestari mangrove, ditetapkannya Perda Kabupaten Lampung Timur Nomor: 03 Tahun 2002 tentang Rehabilitasi Pesisir, Pantai dan Laut dalam Wilayah Kabupaten Lampung Timur, dan terdapat kerjasama antara beberapa instansi dan masyarakat setempat dalam upaya pelestarian mangrove.

Fenomena tanah timbul terjadi di Labuhan Maringgai tepatnya di Desa Margasari sejak tahun 1997 (Himbio Unila, 2014) dan hingga tahun 2013 luasnya telah mencapai 700 ha. Adapun di daerah tanah timbul tersebut kegiatan-kegiatan penanaman mangrove dilaksanakan. Terlaksananya kegiatan-kegiatan penanaman mangrove ini dilatarbelakangi oleh munculnya masyarakat pelestari mangrove di daerah setempat. Masyarakat pelestari mangrove yang digagas oleh Kepala Desa Margasari, Bapak Sukimin (Alm), kemudian bekerjasama dengan Universitas Lampung dalam pengelolaan mangrove sejak tahun 2005. Selanjutnya, pada tahun 2006 Desa Margasari ditetapkan sebagai lokasi pengelolaan hutan mangrove oleh bupati setempat (Tim $L M C$, 2010). Adapun sejak saat itu berbagai instansi ikut berpartisipasi dalam upaya pelestarian mangrove seperti Balai Pengelolaan Hutan Mangrove Wilayah II (BPHM II), dan Japan International Cooperation Agency (JICA). Namun, sebelumnya terdapat pula upaya rehabilitasi mangrove oleh Dinas Kehutanan Provinsi Lampung, Balai Rehabilitasi Lahan dan Konservasi Tanah Provinsi Lampung, dan Dinas Kehutanan Kabupaten Lampung Timur. 


\section{Perubahan Tutupan Hutan Mangrove di Pasir Sakti}

Berdasarkan analisis spasial yang dilakukan di Pasir Sakti pada kurun tahun 19732013, maka dihasilkan kenampakan tutupan hutan mangrove dalam rata-rata interval 10 tahun antara lain sebagai berikut.

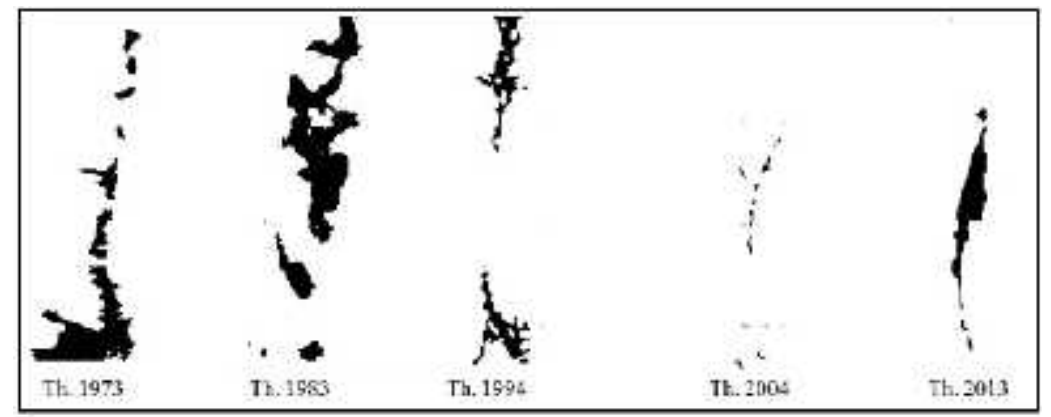

Gambar 6. Perubahan tutupan hutan mangrove di Pasir Sakti tahun 1973-2013

Adapun selain itu, diperoleh pula besaran luasan tutupan hutan mangrove dan persentase perubahannya antara lain disajikan pada tabel berikut.

Tabel 3. Perubahan luasan tutupan hutan mangrove di Pasir Sakti

\begin{tabular}{crrr}
\hline No. & Tahun & $\begin{array}{c}\text { Luas Tutupan hutan mangrove di } \\
\text { Pasir Sakti }\end{array}$ & Besar Perubahan \\
\hline 1 & 1973 & $2.842,33 \mathrm{ha}$ & \\
2 & 1983 & $3.189,66 \mathrm{ha}$ & $+12,22 \%$ \\
3 & 1994 & $787,21 \mathrm{ha}$ & $-75,32 \%$ \\
4 & 2004 & $62,35 \mathrm{ha}$ & $-92,08 \%$ \\
5 & 2013 & $1.062,23 \mathrm{ha}$ & $+1.603,65 \%$ \\
\hline
\end{tabular}

Sumber: Data Primer (2013)

Berdasarkan data yang diperoleh tersebut, maka trend perubahantutupan hutan mangrove di Pasir Sakti dapat disajikan pada gambar berikut.

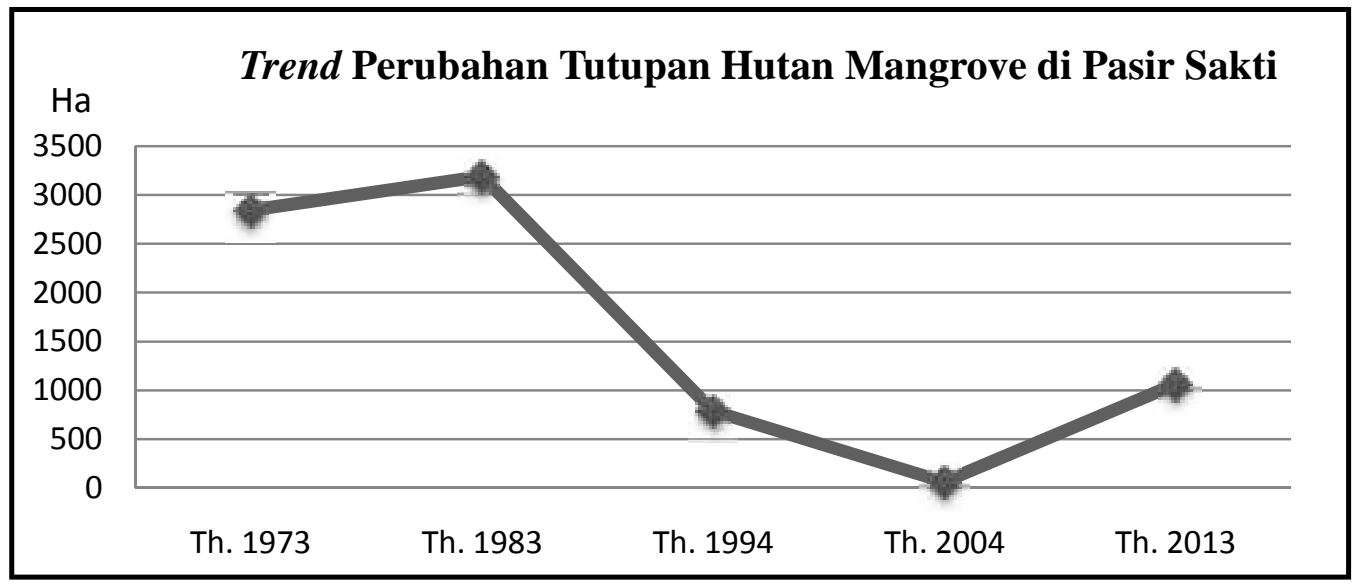

Gambar 7. Trend perubahan luasan tutupan mangrove di Pasir Saktipadatahun 1973-2013

Berdasarkan data yang diperoleh di atas, tampak bahwa perubahan luasan tutupan mangrove cenderung menurun secara signifikan pada rentang tahun 1983 ke tahun 2004 . 
Adapun selain itu, terdapat pula peningkatan luasan tutupan mangrove yang tidak signifikan pada rentang tahun 1973 ke tahun 1983 dan pada tahun 2004 tutupan mangrove nyaris hilang kemudian muncul kembali pada tahun 2013. Trend tersebut selain dapat dilihat dengan data berupa luasan dalam satuan hektar, dapat pula dilihat secara spasial. Secara kenampakan spasial pada rentang tahun 1973 ke tahun 2013 tutupan mangrove memiliki bentuk dan distribusi yang berbeda-beda. Pada tahun 1973 tutupan mangrove cenderung tebal di daerah selatan (hingga Desa Sumur Kucing), sedangkan pada tahun 1983 cenderung tebal di daerah utara (Desa Purworejo hingga Desa Pasir Sakti). Pada tahun 1994 tutupan mangrove berada di daerah utara dan daerah selatan, di Desa Purworejo justru tidak ditemukan adanya tutupan mangrove. Kemudian, pada tahun 2004 tutupan mangrove di Pasir Sakti nyaris lenyap dan hanya tersisa titik-titik kecil saja di Desa Purworejo. Pada tahun 2013 sisa mangrove yang berada di Desa Purworejo muncul dengan kondisi yang terlihat tebal.

Peningkatan luasan tutupan mangrove di Pasir Sakti selama rentang tahun 1973 ke tahun 1983 terjadi seiring dengan sedikitnya aktivitas pemanfaatan sumber daya alam yang terjadi di lokasi setempat. Aktivitas tersebut seperti pembukaan lahan untuk pertanian dan usaha perikanan yang dilakukan oleh kelompok kecil masyarakat (wawancara dengan Bapak Uji, usia 75 tahun). Selain itu pola polygon yang terbentuk dari tutupan hutan mangrove yang luas dengan bentuk kurang teratur merupakan indikasi bahwa mangrove yang ada tersebut masih alami dan belum banyak mengalami gangguan (Fathurrohmah,et al., 2013).

Adapun penurunan luasan tutupan mangrove di Pasir Sakti selama rentang tahun 1983 ke tahun 2004 terjadi seiring dengan adanya aktivitas masyarakat yang lebih besar daripada aktivitas di tahun-tahun sebelumnya yang terjadi di lokasi setempat. Aktivitas tersebut antara lain adalah pembukaan lahan pesisir untuk dijadikan tambak-tambak udang tradisional. Hal yang terjadi selanjutnya adalah tanggul-tanggul tambak yang berhadapan dengan laut hancur oleh abrasi sehingga mempercepat proses penggerusan daratan hingga saat ini (Pariwono, 1999). Abrasi yang terjadi tersebut juga telah menghilangkan pal batas Hutan Lindung (HL) yang ditetapkan oleh Dinas Kehutanan dan Perkebunan Kabupaten Lampung Timur pada tahun 2000 (Muslikah dan Eriza, 2010).

Adapun peningkatan kembali luasan tutupan mangrove di Pasir Sakti selama rentang tahun 2004 ke tahun 2013 terjadi seiring dengan ditetapkannya Perda Kabupaten Lampung Timur Nomor: 03 Tahun 2002 tentang Rehabilitasi Pesisir, Pantai dan Laut dalam Wilayah Kabupaten Lampung Timur serta aktivitas masyarakat pelestari mangrove di daerah setempat. Sebenarnya aktivitas masyarakat pelestari mangrove di Pasir Sakti telah ada sejak tahun 1994 dan pada tahun 1995 telah melakukan penanaman mangrove dan program sylvofishery, namun penanaman dan program tersebut tidak berhasil. Kemudian, pada tahun 2005 kelompok tersebut ikut serta dalam kegiatan sosialisasi tentang hutan mangrove di Desa Margasari, Labuhan Maringgai. Setelah itu kelompok masyarakat pelestari mangrove (Kelompok Tani Mutiara Hijau I) mulai aktif dalam kegiatan-kegiatan pelestarian mangrove dengan didanai oleh Anggaran APBN BPDAS Way Seputih Way Sekampung, Dinas Kehutanan dan Perkebunan Kabupaten Lampung Timur, dan BPHM II. Pada tahun 2011 Kelompok Tani Mutiara Hijau I mulai merintis pembuatan Areal Model Arboretum Mangrove seluas 10 ha, dan pada tahun 2012 kelompok ini mulai merintis pembangunan Kebun Bibit Rakyat (KBR) (Muslikah dan Eriza, 2010). Berbagai upaya pelestarian tersebut mampu mengembalikan luasan tutupan mangrove hingga melampaui luas mangrove 20 tahun sebelumnya.

\section{Perubahan Tutupan Hutan Mangrove di Pesisir Kabupaten Lampung Timur}

Berdasarkan penjelasan di atas, terlihat perbedaan trend perubahan tutupan hutan mangrove di ketiga wilayah di Pesisir Lampung Timur. Trend perubahan tutupan hutan mangrove di TNWK memberntuk kurva tertutup, di Labuhan Maringgai membentuk kurva terbuka, dan di Pasir Sakti membentuk kurva bergelombang. Hal ini mengindikasikan adanya 
perbedaan faktor-faktor pemicu perubahan tutupan mangrove di masing-masing wilayah. Berdasarkan data yang diperoleh,diketahui bahwa di TNWK faktor-faktor tersebut cenderung didominasi oleh pengaruh dari kebijakan dan program dari Kementerian Kehutanan, seperti perubahan status pengelolaan kawasan hingga pembatasan akses masyarakat ke dalam kawasan. Adapun dilihat dari segi etnoekologi, perubahan status pengelolaan kawasan dan pembatasan akses masyarakat ke dalam kawasan yang cenderung mengarah ke upaya konservasi kawasan merupakan interaksi yang bersifat positif bagi luas tutupan mangrove setempat guna mempertahankan serta meningkatkan pertumbuhannya. Sedangkan di Labuhan Maringgai dan Pasir Sakti, tutupan mangrove cenderung dipengaruhi oleh aktivitas sosialekonomi masyarakat setempat. Adapun aktivitas masyarakat setempat di Labuhan Maringgai dan Pasir Sakti di antaranya terdapat pengeksploitasian lahan pesisir kemudian terdapat pula upaya rehabilitasi mangrove setempat. Adapun dilihat dari sisi etnoekologi, pengeksploitasian lahan pesisir tersebut merupakan suatu bentuk interaksi yang cenderung negatif, karena dampak yang terjadi adalah berkurangnya luasan tutupan mangrove.

Pengeksploitasian lahan pesisir di Labuhan Maringgai dan Pasir Sakti umumnya sama, yaitu pengalihfungsian lahan pesisir menjadi lahan pertanian dan perikanan, namun perbedaan yang terdapat di antara keduanya adalah adanya program transmigrasi di Labuhan Maringgai. Program transmigrasi membuat lahan pesisir di Labuhan Maringgai cenderung dimanfaatkan dengan adanya perencanaan terlebih dahulu oleh pemerintah, namun dalam pelaksanaannya kontrol atas pengeksploitasian mangrove tidak diperhatikan.

Selain pengekploitasian lahan pesisir, di Labuhan Maringgai dan Pasir Sakti kini di dalamnya sama-sama terdapat upaya rehabilitasi mangrove. Adapun dilihat dari sisi etnoekologi, upaya rehabilitasi mangrove tersebut merupakan suatu bentuk interaksi yang positif, karena hasil dari upaya tersebut mampu mempertahankan bahkan meningkatkan luasan tutupan mangrove. Upayarehabilitasi tersebut lebih dahulu dirintis oleh masyarakat di Labuhan Maringgai baru kemudian disusul oleh masyarakat di Pasir Sakti. Adapun kemudian, dari segi manajemen upaya rehabilitasi mangrove di Labuhan Maringgai lebih berkembang daripada di Pasir Sakti. Hal tersebut dikarenakan upaya rehabilitasi mangrove di Labuhan Maringgai dilakukan bersama instansi perguruan tinggi (Universitas Lampung) yang tergabung dalam Lampung Mangrove Center bekerjasama dengan berbagai instansi lainnya, sedangkan di Pasir Sakti baru dilakukan oleh kelompok masyarakat setempat saja namun juga didanai oleh berbagai instansi.

Secara keseluruhan pesisir Lampung Timur, tampak bahwa sebagian besar pemicu terjadinya perubahan tutupan mangrove adalah aktivitas masyarakat sekitar dalam memanfaatkan sumberdaya alam setempat. Adapun perubahan yang paling signifikan terjadi pada kurun 1994-2004. Pada kurun tersebut terjadi perambahan di pesisir TNWK dan munculnya dampak dari pembangunan tambak di periode sebelumnya yaitu jebolnya tanggultanggul yang mempercepat terjadinya abrasi. Hal ini disebabkan karena eksploitasi sumberdaya alam dilakukan tanpa memperhitungkan kondisi keseimbangan lingkungan. Menurut Hardin (1968), fenomena tersebut merupakan the tragedy of the commons, di mana setiap masyarakat berkeinginan untuk meraih keuntungan maksimal terhadap suatu sumberdaya alam namun pada akhirnya ketersediaan sumberdaya alam tersebut akan habis dan justru berdampak negatif bagi masyarakat yang mengeksploitasi dan masyarakat lainnya.

Adapun sebagaimana dijelaskan pada pembahasan sebelumnya bahwa terdapat beberapa solusi antara lain terdapat perubahan status kawasan menjadi lebih mantap, penetapan peraturan daerah, penyuluhan dan pemberdayaan masyarakat, dan pengelolaan mangrove oleh kelompok-kelompok masyarakat setempat dan bekerja sama dengan pihakpihak lain. Solusi-solusi tersebut ternyata sesuai dengan pendapat Gardner dan Sterm (1996) dalam mencegah the tragedy of the commons, antara lain penggunaan peraturan pemerintah, aturan-aturan, dan insentif, program pendidikan, pengelolaan berbasis komunitas, serta 
penggunaan daya tarik moral, agama dan etika. Namun, tidak dapat dicegahnya the tragedy of the commons di pesisir Lampung Timur disebabkan karena solusi-solusi tersebut tidak diterapkan secara terintegrasi. Sedangkan apabila solusi-solusi tersebut digunakan sebagai bagian dari berbagai program, baik program rehabilitasi pesisir maupun program pembangunan daerah, tentunya sumberdaya di pesisir Lampung Timur selain menguntungkan masyarakat secara ekonomi, juga tetap berada pada kondisi ekologis yang baik dan lestari.

\section{SIMPULAN}

Perubahan tutupan mangrove Lampung Timur antara lain: (a) tahun 1973-1983 bertambah seluas 2.541,22 ha, terdiri atas penambahan di Taman Nasional Way Kambas (TNWK) seluas 2.740,69 ha atau 21,9\%, pengurangan di Labuhan Maringgai seluas 546,81 ha atau 23,04\%, dan penambahan di Pasir Sakti seluas 347,33 ha atau 12,22\%; (b) tahun 1983-1994 berkurang seluas 4.903,54 ha terdiri atas pengurangan di TNWK seluas 1.301,28 ha atau 8,53\%, pengurangan di Labuhan Maringgai seluas 1.199,81 ha atau 65,69\%, dan pengurangan di Pasir Sakti seluas 2.402,45 ha atau 75,32\%; (c) tahun 1994-2004 berkurang seluas $6.377,11$ ha terdiri atas pengurangan di TNWK seluas 5.723,93 ha atau 41,02\%, penambahan di Labuhan Maringgai seluas 89,68 ha atau 14,79\%, dan pengurangan di Pasir Sakti seluas 742,86 ha atau 92,08\%; (d) tahun 2004-2013 berkurang seluas 3.059,23 ha terdiri atas pengurangan di TNWK seluas $4.505,97$ ha atau 54,75\%, penambahan di Labuhan Maringgai seluas 446,86 ha atau 62,12\%, penambahan 999,88 ha atau 1.603,65\%;

Faktor-faktor pemicu perubahan tutupan hutan mangrove di pesisir Lampung Timur antara lain: (a) terdapat perubahan status kawasan hutan di TNWK; (b) terdapat aktivitas nelayan di dalam kawasan hutan TNWK; (c) terdapat pemberantasan kasus perambahan di TNWK; (d) terjadi abrasi di TNWK, Labuhan Maringgai dan Pasir Sakti; (e) munculnya aktivitas masyarakat pendatang yang membuka hutan mangrove untuk dijadikan ladang padi dan tambak udang tradisional di Labuhan Maringgai dan Pasir Sakti; (f) terdapat program transmigrasi di Labuhan Maringgai; (g) terdapat tanah timbul; (h) munculnya masyarakat pelestari mangrove di Labuhan Maringgai dan Pasir Sakti; (i) ditetapkannya perda tentang rehabilitasi daerah pesisir oleh pemerintah kabupaten; (j) terdapat kerjasama antara beberapa instansi dan masyarakat setempat dalam upaya pelestarian mangrove di Labuhan Maringgai dan Pasir Sakti.

\section{SARAN}

Penelitian selanjutnya perlu dilakukan, terutama yang terkaitdengan analisis vegetasi mangrove. Analisis vegetasi yang umumnya dilakukan secara manual, yaitu melakukan pengukuran langsung di lapangan kini dapat dikombinasikan dengan menggunakan penginderaan jauh dan GIS. Hal tersebut dapat dilakukandi antaranya dengan analisis indeks vegetasi menggunakan Difference Vegetation Index (DVI), Normalized Difference Vegetation Index (NDVI), Ratio Vegetation Index (RVI), Transformed Ratio Vegetation Index (TRVI), dan Transformed Normalized Vegetation Index (TNDVI)(Wijaya, 2005).Analisis vegetasi terhadap hutan mangrove ini diperlukan untuk pemantauan dan inventarisasi mangrove lebih lanjut.

\section{DAFTAR PUSTAKA}

Balai Taman Nasional Way Kambas (BTNWK). 2011. Rencana Strategis Balai Taman Nasional Way Kambas Tahun 2011. Buku. Balai Taman Nasional Way Kambas Labuhan Ratu Lampung Timur. Lampung. I: 3, 25-26 hlm. 
Darmawan, A. 2002. Perubahan tutupan lahan di Cagar Alam Rawa Danau. Skripsi. Fakultas Kehutanan. Institut Pertanian Bogor. Bogor. 4-6 hlm.

Fathurrohmah, S., Karina B. H., Bramantiyo M. 2013. Aplikasi penginderaan jauh untuk pengelolaan hutan mangrove sebagai salah satu sumberdaya wilayah pesisir(Studi Kasus di Delta Sungai Wulan Kabupaten Demak).Jurnal ilmiah. Disampaikan dalam Seminar Nasional Pendayagunaan Informasi Geospatial untuk Optimalisasi Otonomi Daerah 2013. Program Magister Perencanaan Pengelolaan Pesisir dan Daerah Aliran Sungai, Fakultas Geografi, Universitas Gadjah Mada. Jogjakarta. 2 hlm.

Gardner, G. T., Stern, P. C. 1996.Environmental Problems and Human Behavior. Buku. Allyn and Bacon. Boston.

Hardin, G. 1968.The Tragedy of the Commons. Science. 1243-1248. $162 \mathrm{hlm}$.

Himpunan Mahasiswa Biologi (Himbio) Universitas Lampung. 2014. Laporan survey PKSDA XVII Universitas Lampung. Laporan. Situs Hijau Indonesia. Bandar Lampung. 3-5 hlm.

Kenedie, J. 2010. Revisi zonasi Taman Nasional Way Kambas. Laporan. Presentasi Kepala Taman Nasional disampaikan dalam rangka pembahasan revisi zonasi TN Way Kambas di hadapan Tim Pokja Direktorat Konservasi Kawasan Ditjen PHKA. Jakarta. $13 \mathrm{hlm}$.

Muslikah, N., Eriza, A. O. 2010. Masyarakat peduli pelestarian hutan mangrove di Desa Purworejo Pasir Sakti Lampung Timur. WANAMINA (Wahana Berita Mangrove Indonesia). BPHM II. Medan. 27-29hlm.

Nugroho, A.S., Fujimura, M., dan Inaoke, T. 2010. Evaluation of transmigration (transmigrasi) in Indonesia: changes in socioeconomic status, community health and environmental qualities of two specific migrant populations.Thesis. The Graduate School of Agriculture Science. Kagoshima University. Kagoshima. Japan. 21-22 pp.

Pariwono, J. I. 1999. Kondisi Oseanografi Perairan Pesisir Lampung. Buku. CRC/URI CRMP NRM Secertariat. Jakarta. 21hlm.

Pemerintah Daerah Kabupaten Lampung Timur. 2002. Peraturan Daerah Kabupaten Lampung Timur Nomor: 03 tahun 2002 tentang Rehabilitasi Pesisir, Pantai dan Laut dalam Wilayah Kabupaten Lampung Timur. Sukadana. Lampung Timur. 1-9 hlm.

Priyanto. 2012. Dalam berita: 48\% hutan 'mangrove' di Lampung rusak. Harian Lampung Post. Diakses melalui web pada 28 Agustus 2013, pukul 4:17 WIB. http://watala.org/new/?p=156. 1 halaman.

Tim Lampung Mangrove Center. 2010. Pengelolaan kolaboratif hutan mangrove berbasis pemerintah, masyarakat dan perguruan tinggi. Profil (Portofolio) Lampung Mangrove Center. Lampung Mangrove Center Lembaga Penelitian Universitas Lampung. Diakses melalui web pada 28 Maret 2013, pukul 13:33 WIB. http://xa.yimg.com/kq/groups/2395425/1427403687/name/PROFIL+LAMPUNG+MA NGROVE+CENTER.pdf/. 6-9 hlm.

United States Geological Survey (USGS) EarthExplorer.United States Geological Survey. Diakses melalui web secara berkala selama Oktober 2013 - Maret 2014.http://earthexplorer.usgs.gov/.

Watala. 2009. 48\% hutan 'mangrove' di Lampung rusak. Harian Lampung Post. Diakses melalui web pada pada 27 Maret 2013, pukul 20:35 WIB. http://watala.org/new/?p=156. $1 \mathrm{hlm}$.

Wetlands. 2009. Luas kawasan mangrove per kabupaten.Wetlands. Diakses melalui web pada 30 Agustus 2013, pukul 15:35 WIB. http://indonesia.wetlands.org/Portals/28/PDF/Luas\%20Kawasan\%20Mangrove\%20Pe r\%20Kabupaten.pdf. $3 \mathrm{hlm}$. 
Wijaya, S.W. 2005. Aplikasi penginderaan jauh dengan citra satelit Quickbird untuk pemetaan mangrove di Pulau Karimunjawa, Kabupaten Jepara, Jawa Tengah. Skripsi. Program Studi Ilmu Kelautan. Fakultas Perikanan Dan Ilmu Kelautan. Institut Pertanian Bogor. Bogor. 27 hlm.

Wiryawan, B., B. Marsden, H.A. Susanto, A.K. Mahi, M. Ahmad, H. Poespitasari. 1999. Atlas Sumberdaya Wilayah Pesisir Lampung. Buku. Pemerintah Daerah Provinsi Lampung dengan Proyek Pesisir (Coastal Resources Center, University of Rhode Island dan Pusat Kajian Sumberdaya Pesisir dan Lautan, Institut Pertanian Bogor). Bandar Lampung. 57-58 hlm. 
Vol. 2 No. 3, September 2014 (1II-124)

Halaman ini sengaja dikosongkan 